\title{
Pelé, futebol e ditadura: uma resenha do documentário "Pelé"
}

\author{
iD (9) Daniel Giordani Vasques \\ Universidade Federal do Rio Grande do Sul - UFRGS, Porto Alegre, RS, Brasil \\ dgvasques@hotmail.com
}

iD (9) Flávio Py Mariante Neto

Universidade Luterana do Brasil - ULBRA, Canoas, RS, Brasil flaviomariante@hotmail.com

\begin{abstract}
Resumo: Este texto trata-se de uma resenha crítica do documentário "Pelé", lançado pela Netflix em fevereiro de 2021. A obra apresenta a carreira futebolística de Pelé entre as Copas de 1958 e 1970 e, para isso, mostra as tensões em torno do personagem e do contexto político brasileiro. A partir dessas reflexões e da sua recorrente comparação com Muhammad Ali, perguntamos: - Por que Pelé teve uma postura não combativa em relação a questões políticas de sua época? Com base na teoria do processo civilizador, procurou-se responder em observância às relações de poder que situaram Pelé como membro da sociedade estabelecida e à configuração social que, formada por futebol/esporte, Estado e povo, e na governança de um regime autoritário e violento, diminuiu os graus de liberdade para Pelé agir.
\end{abstract}

Palavras-chave: Pelé; Futebol; Configuração; Ditadura;

Submetido em: 12-03-2021

Aceito em: 12-04-2021

A câmera apresenta Pelé em seu jogo de despedida do futebol em Nova York em outubro de 1977, quando, pelo Cosmos, jogou contra o Santos. A imagem mostra Pelé em campo com um microfone e os dedos em "V" pronunciando "love, love, love", frase que ficou marcada na canção homônima de Caetano Veloso. Entre as palavras ditas lentamente, a câmera mostra no estádio 
Pelé, futebol e ditadura: uma resenha do documentário "Pelé"

Daniel Giordani Vasques • Flávio Py Mariante Neto

Muhammad Ali, que, sentado, observa Pelé e o estádio lotado a repetir as suas palavras com um olhar aparentemente sereno.

Observar os dois personagens do esporte mundial suscita a comparação entre eles, sobretudo no que se refere à dimensão política das suas ações. Enquanto Muhammad Ali se posicionou contra os padrões estabelecidos de sua época em questões de religião, de racismo e de patriotismo (MARIANTE NETO et al., 2010), Pelé foi acusado e criticado por não combater a ditadura brasileira e não lutar pela igualdade racial.

O documentário Pelé, dirigido por David Tryhorn e Ben Nicholas e lançado mundialmente pela Netflix em 23 de fevereiro de 2021, apresenta a trajetória desse atleta da Copa de 1958 à Copa de 1970, contextualiza a cena política do Brasil e reflete tensões existentes à época. Para isso, resgata filmagens antigas de Pelé e de outros atletas, treinadores e dirigentes, que se intercalam com uma entrevista recente de Pelé e de outras com jornalistas, atletas, políticos e personalidades brasileiras. Nesse contexto, o filme apresenta as acusações por ele não ter atuado de modo combativo, bem como sugere explicações relacionadas ao contexto brasileiro da época.

Nesta resenha, nos propomos a dialogar sobre Pelé a partir da teoria do processo civilizador de Norbert Elias (2011), que entende o controle das pulsões como elemento central na formação da personalidade e que propõe a relação entre a psicogênese e a sociogênese como fundamental para compreender as ações dos sujeitos como resultantes de processos de incorporação. Além disso, Elias e Scotson (2000) mostram que as disputas de poder possibilitam que certos grupos atuem como estabelecidos - "reconhecido como uma boa sociedade, mais poderosa e melhor" (p. 7) - e outros acabem se caracterizando como outsiders - ou seja, um grupo heterogêneo e difuso, um não-grupo. Ademais, o olhar configuracional (ELIAS, 2005), além de mostrar os elementos que sustentam as ações, possibilita visualizar que o grau de liberdade do indivíduo é resultante do seu deslocamento dentro da configuração. 
Pelé, futebol e ditadura: uma resenha do documentário "Pelé" Daniel Giordani Vasques • Flávio Py Mariante Neto

A partir disso, questionamos: - Por que Pelé teve uma postura não combativa em relação a questões políticas de sua época? A análise desse ator social - inspirada nos moldes eliasianos de construção de personagens como modo de entender a configuração - exige analisar a configuração brasileira que permitiu o surgimento e o reconhecimento de Pelé. O texto se baseia em três elementos que, de acordo com o documentário, sustentam a trajetória de Pelé: o esporte/futebol, o Estado e o povo.

No que se refere ao esporte/futebol, as narrativas do documentário sublinham que Pelé foi o melhor jogador de todos os tempos. Essa argumentação possibilita entender a performance como uma condição necessária para que esse personagem alcançasse tal reconhecimento. Como Elias (1995) fala de Mozart, Pelé era um "gênio", um ser humano incrivelmente talentoso e criativo, mas que, neste caso, diferentemente daquele, nasceu em uma sociedade que o reconheceu e permitiu sua ascensão.

A estratégia narrativa mostra os equilíbrios e desequilíbrios de tensão existentes nas quatro Copas disputadas por Pelé: em 1958 a seleção lidou com a frustração de 1950 e o "complexo de vira-lata"1; em 1962 Pelé se lesionou no segundo jogo e não jogou mais; em 1966 os marcadores foram violentos e a arbitragem permitiu; em 1970 ele chegou desacreditado e o treinador anterior não queria escalá-lo. A reconstrução das memórias de tais tensões sugere que, ao menos até 1970, a sua capacidade como jogador era questionada, tanto que o treinador não queria convocá-lo. É sobretudo nessa Copa que ele se torna unanimidade.

O futebol era na época de Pelé - e, em certa medida, permanece sendo - um espaço social cuja configuração permitia que indivíduos negros obtivessem destaque e reconhecimento. No entanto, para isso era necessário que o jogador negro não se posicionasse contra os valores da sociedade estabelecida. Pelé foi acusado de aceitar esse papel. No filme, Paulo Cézar Caju afirma que "ele tinha o comportamento do 'negro sim senhor', do negro que é submis-

1 Expressão criada por Nelson Rodrigues, originada na derrota da seleção brasileira para o Uruguai na final da Copa de 1950, para designar um estado de inferioridade em que o brasileiro se coloca, voluntariamente, diante de outros povos. 
Pelé, futebol e ditadura: uma resenha do documentário "Pelé"

Daniel Giordani Vasques • Flávio Py Mariante Neto

so, que aceita tudo, que não contesta, que não critica, que não julga", o que reitera Pelé como membro da sociedade estabelecida. Certamente a sociedade estabelecida relutaria em aceitar no futebol negros que a combatessem.

O Estado brasileiro é elemento fundamental da configuração, e o documentário apresenta dois momentos. O primeiro é democrático e representado nas conquistas de 1958 e 1962, período em que o país se destacava e construía uma imagem internacional a partir de diferentes feitos: a bossa nova, o cinema novo, a construção de Brasília, etc. Tais conquistas alimentavam sentimentos de orgulho e de emancipação nacional. A Copa de 1970 representa, por sua vez, outro momento do Estado, já que o país estava em uma ditadura cívico-militar sob a forte repressão do Al-5 do governo Médici, que retirou as liberdades e permitiu que pessoas fossem presas sem causa. Essa conquista atendeu aos interesses do Estado que, como mostra o filme, agiu para escalar Pelé e para ganhar a Copa.

A Copa de 1970 ocorre, portanto, posteriormente à mudança na configuração que diminuiu a margem de ação dos atores. Os interlocutores afirmam que Pelé nunca foi um obstáculo para o regime militar e que os governos sempre buscaram-no para apoiar um lado ou outro. Pelé afirma no documentário que sabia de "muitas coisas" das atrocidades da ditadura, mas que de outras não tinha certeza; ao mesmo tempo, ressalta que sentiu a pressão do governo para jogar essa Copa e que, naquele momento, "não deu pra fazer outra coisa". Essa análise reforça seu lugar como membro da sociedade estabelecida mas, ao mesmo tempo, ressalta que a sua liberdade de ação para combater o regime militar era relativamente pequena.

Ao comparar as ações de Pelé com as de Muhammad Ali (MARIANTE NETO et al., 2010) diante do Estado, é possível identificar elementos distintivos. Enquanto Ali luta contra o governo em torno da guerra do Vietnã e se diz não-patriota, Pelé abraça o ditador Médici após seu gol mil e admite não ter sido forçado a fazê-lo. Enquanto Ali luta no Zaire como outsider e representa os 
Pelé, futebol e ditadura: uma resenha do documentário "Pelé"

Daniel Giordani Vasques • Flávio Py Mariante Neto

movimentos negro e islâmico, as excursões de Pelé ao exterior são formas de promoção de um Brasil unicizado pelos militares. Tais comparações, no entanto, são superficiais se não for considerado que o Estado brasileiro, como elemento da configuração, agia à margem da lei, de modo violento e repressor, com aqueles que dele discordavam, o que não acontecia de forma similar no país de Ali. Desse modo, Pelé é ao mesmo tempo um estabelecido e um personagem circunspecto à configuração da sociedade brasileira.

O povo brasileiro é o terceiro elemento da configuração. $O$ futebol é tornado elemento de identificação da população, uma instituição nacional. Pelé é produto de uma importante época do país, da transição dos anos 1950 para os 1960, de "um Brasil que acreditava nele". Os interlocutores mostram no documentário que nesse período democrático o futebol, a seleção brasileira e Pelé simbolizavam e incorporavam nos indivíduos elementos associados ao "orgulho nacional" e à identificação de "país moderno". No sentimento do povo, Pelé representava a resolução do complexo de vira-lata brasileiro.

Para Elias (1997), o habitus é um contraponto à ideia de identidade nacional, mais rígida, fixa e, portanto, menos mutável. O habitus é uma segunda natureza, no sentido de que são inculcados nos indivíduos valores, regras e normas que os fazem agir. Tal processo ocorre a partir de práticas cotidianas que perfazem uma "pedagogia tácita", na qual é realizada uma incorporação espontânea dos ditames configuracionais, que no futebol se traduzem em momentos de tensão-excitação agradável.

Com base nessa lógica, futebol e Pelé foram incorporados no povo de forma a comporem um habitus brasileiro, fazendo com que grande parte da sociedade torcesse para o "Brasil de Pelé" na Copa de 1970 de forma quase que "automática", apesar de possíveis ganhos da ditadura com isso. Ratificando essa análise, o jornalista José Trajano pondera que tentou torcer contra o Brasil nessa Copa, mas que ao chegar no México "não teve coragem". Essa cena apresenta uma importante tensão da época entre o habitus brasileiro do futebol e o Estado ditatorial do país, e acaba por re- 
Pelé, futebol e ditadura: uma resenha do documentário "Pelé"

Daniel Giordani Vasques • Flávio Py Mariante Neto

fletir o sentimento do povo, ao menos dos críticos do regime. Ao fim, Pelé, a seleção e a ditadura ganharam; o país perdeu porque deu respiro àquele regime.

Uma série de argumentos são trazidos no documentário para justificar porque Pelé não combateu a ditadura militar. O mais relevante deles vem de Juca Kfouri, que usa da comparação com Muhammad Ali para dizer que ele "foi diferente. Eu bato palma! [...] [ele] sabia que ao ser preso por deserção, ele não corria o menor risco de ser maltratado, de ser torturado. O Pelé não tinha essa garantia".

Essa fala ratifica que Pelé tinha, comparativamente, mais limitações para agir, sobretudo por estar em outra configuração social. A configuração formada por esporte/futebol, Estado e povo, que sustentou a existência e as ações (e inações) de Pelé, limitou as suas possibilidades. Por fim, a existência de um regime autoritário e violento diminuiu ainda mais os graus de liberdade de Pelé dentro daquela configuração, o que reforça a necessidade de atenção do povo e de luta pela manutenção de um Estado democrático.

\section{Referências}

ELIAS, Norbert. Mozart: sociologia de um gênio. Rio de Janeiro: Jorge Zahar, 1995.

ELIAS, Norbert. Os alemães: a luta pelo poder e a evolução do habitus nos séculos XIX e XX. Rio de Janeiro: Jorge Zahar, 1997.

ELIAS, Norbert. 0 processo civilizador, volume 1: uma história dos costumes. Rio de Janeiro: Zahar, 2011.

ELIAS, Norbert. Introdução à sociologia. Lisboa: Edições 70, 2005.

ELIAS, Norbert; SCOTSON, John L. Os estabelecidos e os outsiders: sociologia das relações de poder a partir de uma pequena sociedade. Rio de Janeiro: Jorge Zahar, 2000. 
Pelé, futebol e ditadura: uma resenha do documentário "Pelé" Daniel Giordani Vasques • Flávio Py Mariante Neto

MARIANTE NETO, Flávio Py; MIRANDA, Carlos Fabre; MYSKIW, Mauro; STIGGER, Marco Paulo. Muhammad Ali, um outsider na sociedade americana? Revista Brasileira de Ciências do Esporte, v.32, n.2-4, p.105-122, 2010. Disponível em: http://revista.cbce.org.br/index.php/RBCE/article/view/602/593. Acesso em: 12 mar. 2021.

PELÉ. Direção de David Tryhorn e Ben Nicholas. Netflix, 2021.

\title{
Publisher
}

\begin{abstract}
Universidade Federal de Goiás. Faculdade de Educação Física e Dança. Publicação no Portal de Periódicos UFG. As ideias expressadas neste artigo são de responsabilidade de seus autores, não representando, necessariamente, a opinião dos editores ou da universidade.
\end{abstract}

